\title{
O PENSAMENTO DE FOUCAULT E SUAS CONTRIBUIÇÕES PARA A EDUCAÇÃO*
}

Antonio Flavio Barbosa Moreira ${ }^{* *}$

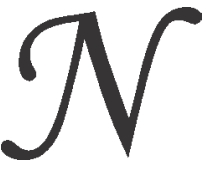

ão é tarefa fácil resumir, de modo simples, claro, preciso e rigoroso, o pensamento de um autor de textos densos e complexos como Michel Foucault, nos quais idéias, categorias e métodos se elaboram, apresentam, transformam, aprofundam e enriquecem ao longo do tempo e da obra. A ausência de sistematização dos conceitos e das idéias que norteiam as análises, bem como os diferentes sentidos que certas categorias assumem em distintos escritos, tornam a tarefa similar à do detetive que, envolto em intrincadas e confusas pistas, procura ordenar, classificar, averiguar e compreender os fatos ocorridos. Diferentemente do detetive, porém, quem procura sistematizar o trabalho de um "filósofo edificante" não chega jamais à "verdade" dos fatos, mas sim a uma leitura, a uma possibilidade, entre outras, de exploração.

Mais difícil ainda, parece-me, é pensar a vasta obra de Foucault tendo em vista sua aplicação a um campo amplo, mutável e multifacetado como a educação. À dificuldade de condensar idéias agrega-se a de refletir como elas podem ser úteis na problematização de práticas e teorias educacionais. Foi a essa tarefa que se dedicou Alfredo Veiga-Neto em seu relevante livro Foucault e a educação. O autor é, indiscutivelmente, o pesquisador brasileiro do campo da educação que mais e melhor tem trabalhado, em análises de questóes do campo, com o pensamento do filósofo francês. Daí minhas fortes expectativas ao iniciar a leitura, plenamente atendidas ao seu final.

\footnotetext{
* Resenha do livro Foucault e a educação, de autoria de Alfredo Veiga-Neto (Belo Horizonte: Autêntica, 2003).

** Antonio Flavio Barbosa Moreira é doutor e professor titular da Universidade Católica de Petrópolis (UCP) e pesquisador associado da Universidade Federal do Rio de Janeiro (UFRJ). E-mail:afmcju@infolink.com.br
}

Educ. Soc., Campinas, vol. 26, n. 90, p. 309-313, Jan./Abr. 2005 
$\mathrm{Na}$ apresentação do texto, Veiga-Neto reconhece faltar um livro que, "de forma acessível e didática, não apenas explicasse sua filosofia e mostrasse o que ele [Foucault] escreveu sobre o sujeito, os saberes, os poderes e as instituições modernas, mas que também discutisse o que se pode e o que não se pode fazer com ele e a partir dele e o quão produtivo tudo isso é para a Educação" (p. 8, grifos do autor). Felizmente, tal livro não falta mais: é este que ora recomendo.

O primeiro capítulo inicia-se situando Foucault, ainda que ressalvando as dificuldades e os riscos envolvidos nesse propósito, bem como a necessidade de evitar esquematismos e engessamentos. Alerta para o fato de que não é muito pertinente falar em um método foucaultiano ou em uma teoria foucaultiana, a não ser que entendamos os dois termos de modo diverso do que tradicionalmente se faz. Algumas sugestōes sobre como melhor aproveitar o pensamento de Foucault são então dadas. O capítulo encerra-se com considerações sobre distanciamentos e aproximações entre Foucault e outros autores, e sobre perspectivas.

O segundo capítulo discute, em seu começo, as três fases usualmente identificadas no pensamento de Foucault por seus comentaristas - arqueologia, genealogia e ética. Tal sistematização combina critérios metodológicos e cronológicos, procurando evidenciar que a cada fase corresponde um problema principal e uma metodologia. Em razão de problemas nessa sistematização e em decorrência do caráter não-sistemático da obra de Foucault, Veiga-Neto opta por utilizar, em vez de fases ou etapas, a expressão "domínios foucaultianos" para designar "ser-saber", "ser-poder" e "ser-consigo".

No terceiro capítulo o foco é o ser-saber. O autor comenta que, nesse domínio, Foucault faz uma arqueologia dos sistemas de procedimentos que têm por fim produzir, distribuir, fazer circular e regular enunciados, bem como se preocupa em isolar o nível das práticas discursivas e formular regras de produção e de mudança dessas práticas. Ao final do capítulo, apresentam-se algumas das possibilidades de aplicação da arqueologia na pesquisa educacional.

No quarto capítulo, as atenções voltam-se para o segundo domínio, em que o interesse é o poder, visto na qualidade de elemento capaz de explicar como os saberes são produzidos e como nos constituímos na articulação entre poder e saber. Ou seja, a genealogia, como um tipo especial de história, é o tema central do capítulo. Mais uma vez Veiga-Neto 
permite que se veja como o filósofo pode ser útil para o estudo de questôes educacionais.

O quinto capítulo aborda o terceiro domínio - o ser-consigo. Tal domínio trata da relação de cada um consigo próprio - com o sexo ou por meio do sexo - e de como se constitui e emerge a subjetividade. $\mathrm{Ou}$ seja, trata da ética, entendida como a "relação de si para consigo". Mais uma vez, mostram-se múltiplas as possibilidades de aplicação das contribuições desse domínio nas práticas pedagógicas e nas investigações sobre educação.

O sexto capítulo focaliza "linguagem”, "discurso", "enunciado", "arquivo", "episteme", alguns dos temas foucaultianos. Além de procurar tornar acessível ao leitor como o filósofo entende tais termos, Veiga-Neto caracteriza a análise do discurso do ponto de vista foucaultiano, destacando que ela não se situa entre os pólos opostos e demarcados: de um lado pela filosofia analítica, de outro pela hermenêutica. $\mathrm{Na}$ perspectiva foucaultiana, o analista não se deve ocupar nem com conteúdos de verdade nem com significados ocultos. $\mathrm{O}$ capítulo aborda ainda os regimes de verdade definidos pelos discursos, regimes esses que determinam o verdadeiro e o não-verdadeiro.

O sétimo capítulo enfoca o sujeito. Foucault dá adeus ao sujeito "desde sempre aî" da modernidade e analisa os modos de subjetivação que transformam os seres humanos em sujeitos: "(...) nos tornamos sujeitos pelos modos de investigação, pelas práticas divisórias e pelos modos de transformação que os outros aplicam e que nós aplicamos sobre nós mesmos" (Veiga-Neto, 2003, p. 136). Inúmeros estudos no campo da educação têm permitido que se compreenda como práticas, arranjos e artefatos pedagógicos instituíram e continuam a instituir o sujeito.

O oitavo capítulo ilumina o poder-saber. Para Foucault, os saberes engendram-se e organizam-se de modo que atendam a uma "vontade de poder". O interesse de Foucault é o poder onde ele se manifesta, ou seja, é o micropoder que se exerce (não que se detém) e que se distribui capilarmente. Importa realçar a positividade do poder, entendida como propriedade de produzir alguma coisa. Buscando elucidar como se deve entender a resistência na perspectiva foucaultiana, Veiga-Neto sustenta que o poder se dispõe em uma rede, na qual há pontos de resistência, minúsculos, transitórios e móveis. "A resistência ao poder não é a antítese do 
poder, não é o outro do poder, mas é o outro numa relação de poder - e não de uma relação de poder" (p. 151-152, grifos do autor).

Poder e saber, como dois lados do mesmo processo, entrecruzamse no sujeito, seu produto concreto. Não há relação de poder sem a constituição de um campo de saber, nem saber que não pressuponha e não constitua relações de poder. Foucault, em vez de considerar que só há saber na ausência de relações de poder, considera que o poder produz saber. Para Veiga-Neto, tal perspectiva expulsa do campo da educação o sujeito epistêmico, que tanto agrada aos construtivistas.

No capítulo nove encontra-se uma cronologia foucaultiana, em que estão listados anos e acontecimentos importantes da vida do filósofo. No décimo e último capítulo estão relacionados sites que podem ser consultados pelos que o estudam.

O livro de Veiga-Neto, ao orientar o leitor em uma incursão pelo denso pensamento do filósofo francês, revela-se bastante oportuno. Dado o intenso uso (por vezes abuso) que se tem feito desse pensamento em estudos sobre educação, é de extrema pertinência o esforço por aclarar categorias, caracterizar domínios, esclarecer métodos e questões, esmiuçar possíveis contribuições. Principalmente quando tal esforço é bem-sucedido. Ainda, é de grande valia a apresentação de investigações desenvolvidas com base em Foucault, assim como a sugestão de leituras complementares.

Considerando-se particularmente o campo do currículo, a leitura propicia a certeza de que muito há ainda a ser bebido na fonte foucaultiana. É indiscutível que reflexões sobre saber, poder, subjetividade, ética, linguagem, discurso, tão caras ao filósofo, são indispensáveis para os que se dedicam ao ofício de pensar e fazer currículos, e que reconhecem o quanto as complexas práticas e relações implicadas nessas tarefas ainda precisam ser problematizadas e compreendidas. Aliás, a grande influência de Foucault nos estudos sobre currículo confirma esse ponto de vista.

Sem que me tenha dedicado com maior intensidade ao estudo do instigante pensador francês, algumas perguntas sempre me vieram à mente durante a leitura de alguns de seus livros e de estudos nele inspirados. Será que Foucault não exagera a submissão de pessoas a sutis e produtivos mecanismos de poder? Mesmo que se diga que a resistência se associa ao poder, por que tão pouca atenção a estratégias de resistência? Por que nenhuma atenção ao poder visível que emana do Estado e que responde 
por coerções e restrições que sentimos na pele? Por que a ausência de preocupação com as práticas "concretas", vividas por pessoas tramando, fazendo, dizendo coisas e lutando por elas? Por que a negligência com possíveis esforços de transformação das estruturas vigentes? Por que o foco no discurso precisa colocar na penumbra a materialidade do existente?

Para quem, como eu, enreda-se com tais perguntas, Foucault e a educação incomoda. E assim o faz porque torna evidente que as críticas a Foucault precisam ser mais bem elaboradas. Assim o faz porque convida, com insistência, a um urgente e mais fundo mergulho no vigoroso pensamento desse grande filósofo contemporâneo. Difícil recusar convite tão sedutor! 